\title{
Papers
}

Don Peppers is a partner of Peppers and Rogers Group, a strategic marketing and consulting firm based in Stamford, Connecticut. Martha Rogers is also a partner of the group as well as an adjunct professor at the Fuqua School of Business at Duke University. Together they have written seminal works in the fields of Customer Relationship Management and interactive marketing

Keywords: Customers, one-to-one marketing, learning relationship, IDIC, trusted agent, customer interaction centre
Don Peppers,

Partner,

Peppers and Rogers Group,

470 West Avenue,

Stamford CT 06902,

USA

\section{Build a one-to-one learning relationship with your customers}

\author{
Don Peppers and Martha Rogers \\ Date received (in revised form): 17 November 1999
}

\begin{abstract}
As companies around the globe race to develop more loyal and profitable customer relationships, the competition is fuelling a spectacular burst of technological growth. At the heart of this rapid expansion is one-to-one marketing, a four-step, customer-focused strategy that builds long-term relationships with customers that will generate higher margins, increased customer loyalty and greater customer satisfaction. One-to-one marketing was pioneered in 1993 by Don Peppers and Martha Rogers.
\end{abstract}

Today's Interactive Age customers are accustomed to having their needs met immediately, conveniently and inexpensively. That's why, for many people, contacting customer service representatives can be an excruciating experience. Between navigating lengthy menus of pushbutton options, waiting on hold for what seems like an eternity, never getting a reply to an e-mail, and not having you or your problems remembered the next time you call back, it's no wonder many consumers think customer 'service' is a cruel joke.

However, for customers of First Direct, a British bank that deals with people only by telephone, dialling customer service is rarely a sour experience. As part of training for their jobs, every one of First Direct's customer service reps is blindfolded, handed a real lemon and given time to get to know the fruit's shape and feel. Then the lemons are placed in a bowl and the reps, still blindfolded, are asked to find the lemon they just fondled. Getting the reps to interact intimately with their lemons is how First Direct emphasises the importance of getting to know each customer.

Are you prepared to get to know each of your customers on an individual basis? If your company invites customers to offer their comments or ask questions through a toll-free phone number, e-mail or your website, are you confident that you're mining that critical feedback in the best possible way? More important, does your company make interacting with customers an integral part of a plan to put you in a position of trust in the customer's mind? If your answer to these questions is no, then you're not only going to miss out on building strong and loyal customer relationships - you're going to drive customers to your competitors.

For a company to compete and to gain a customer's trust, it must be able to integrate every customer interaction from any source - phone, fax, 
Peppers and Rogers

\section{From call centre to customer interaction centre}

\section{The learning relationship}

e-mail or Web. This requires companies to transform lowly institutions like the traditional call centre into a customer interaction centre - a much more powerful and important business tool that allows individuals to have any kind of interaction with your company using whatever communications medium they choose. In real life, this might actually mean your customer service reps would be conversing with customers from one minute to the next not only on the phone, but also through e-mail or a secure Web-based chat room. Whether they are making a purchase, checking the status of new accounts, inquiring about current orders, asking for information about new products, or seeking technical support, customers should find an interaction centre to be a seamlessly integrated experience.

One of the most important purposes of interacting with customers, of course, is to strengthen and deepen your relationships with them - to create ongoing, increasingly rich, one-to-one relationships with individual customers. Customers engaged in such relationships will remain more loyal, and will allow you to protect your unit margins more effectively. When a customer tells you something about himself or herself - how he wants to be treated, the type of service or product he needs - and then you customise your offering to that customer to take account of this preference, a relationship is started. The more the customer tells you, the more valuable you will become to him, provided you continue to adjust your product or service to meet his more and more specific, individual needs.

We call this a 'learning relationship'. It is a relationship that gets smarter and smarter with every interaction. Like any relationship, a oneto-one learning relationship builds a context of its own that becomes richer and deeper as time goes on. The deeper the relationship's context, the more efficiently and easily the parties will communicate with each other. In the same way that two long-time business partners, or a husband and wife, might communicate in a 'shorthand' that is all but impenetrable to outside observers, a customer and a company, when engaged in an ongoing learning relationship, will simply find it more convenient and cost-efficient to do business together. A learning relationship not only increases your value to the customer, but it predisposes the customer to want to remain loyal to you, rather than going to the trouble of trying to re-teach your competitor everything he has already taught you about his needs and preferences.

Developing learning relationships is always beneficial, no matter what kind of company you have. But there are some companies for whom it seems to be easier than for others. Companies that have direct relationships and contact with their customers already, for instance, have less channel conflict to overcome, removing one of the barriers of implementing one-to-one marketing. Businesses that routinely acquire a lot of information about their customers also have an easier time with one-to-one marketing. A final consideration is the degree to which a business's customer base consists of customers with diverse needs. The more different a customer's needs are from others, the more beneficial it is for a business to create a relationship based on remembering those needs from interaction to interaction.

Using these criteria, banks, brokerage firms, cruise lines and professional 


\section{Creating an 'extended enterprise'}

\section{Making CRM a reality}

services firms all qualify as immediate candidates for creating learning relationships with their customers. Two other types of industries - airlines and telecoms companies - each have a direct connection with customers and generate a great deal of customer data, but have customer bases characterised by relatively uniform needs. In businesses such as this, a company must 'expand the need set' of its customers, stepping back from the actual service or product being sold, and trying to focus more on the problem being solved. An airline, for instance, might fashion a learning relationship out of the on-board amenities, seating preferences and ground arrangements usually needed by a customer. A telecoms company, on the other hand, might offer customised invoicing and cost distribution to a business customer. Vodac, a South African mobile phone company, does just this. Businesses can download an invoice spreadsheet, allocate their telecoms costs, and then Vodac will take the spreadsheet back, promising to issue next month's invoice with the costs pre-distributed.

One-to-one marketing is possible for companies that operate through indirect channels, as well. One strategy is to treat the channel partner as a part of the 'extended enterprise', using interactive technology to expand the reach of the firm. Great Plains Software, for instance, is a Minnesota-based company that sells accounting applications operated on Microsoft SQL servers for medium-sized firms, and sells exclusively through its value-added resellers. These channel members are all given password-protected sections in the Great Plains Software website where they can call down checklists for how to run consulting meetings, place jobs, hire people, get courses and book education. They can search complete records of a customer they're visiting, right down to the call logs from the previous night at the customer interaction centre. All of this is an effort on Great Plains' part to create stronger, deeper relationships with its channel partners, who now have more loyalty to Great Plains than they would somewhere else.

Whether you call it 'one-to-one marketing' or 'customer relationship management' or 'customer intimacy', this type of strategy is no longer just a dream - companies can do it now. Up until five or ten years ago the whole CRM idea was beyond the capability of most companies. It's been made possible primarily by three important computer technologies at work: databases, interactivity, and mass customisation.

In the last few years, database technology has advanced to the point where companies can now instantaneously access the individual records of a single customer, among millions. Interactivity allows customers to interact with marketers directly, through call centres or websites, through point-of-purchase and frequent-buyer programmes, or through automated sales-force tools that enable a salesperson with a laptop to capture the details of customer interactions immediately into a customer database. Mass customisation, or the digitised mass production of goods and services in lot sizes of one, is the third enabling technology. Mass customisation is very different from customisation. It operates by reducing the production or service-delivery process into components or modules, and then digitally combining those modules. One of the most successful examples of this is Dell Computer, which builds made-to-order personal 
Identify

\section{Differentiate}

Interact computers from a customer's stated needs and preferences.

Using these technologies to build one-to-one relationships requires a four-step implementation process, and by applying this methodology directly to the task of managing and measuring the success of a customer interaction centre, you can more effectively harness the benefits of customer interactivity to begin with. This is often called the 'IDIC' methodology, four letters that stand for the four key words in the implementation process - Identify, Differentiate, Interact, and Customise.

- Identify your customers. You can only have a relationship with an individual, not with a population. Therefore, identifying individual customers is a critical first step. At an interaction centre, this means trying to identify callers and website visitors as quickly, as costefficiently, and as universally as possible. Use caller-ID technology and make customer records quickly available to the customer service reps who answer the phones. At your website, provide benefits to visitors who register themselves - perhaps in the form of more personalised information, or a more relevant service, or even a premium or discount on future purchases. In addition, use your customer interaction centre as a 'catchment' area to capture the identities of otherwise anonymous product purchasers who have been encouraged to call in for service, to register their product, or to claim a benefit. Stamp your URL and your toll-free number on every single product you sell, so when customers do need to contact you, they can do it easily and you can identify even more of them. Store individual customer information in your database to make future interactions easier.

- Differentiate your customers. Customers have different values to you, and they need different things from you. Once you identify a customer, the next step in turning this into a genuine relationship is to try to figure out where this customer fits in the overall hierarchy of values, and what this customer needs that may be different from what many others need. One small step your interaction centre can take is simply to begin differentiating more profitable customers from other customers, and singling them out for better or more personalised treatment. Dell Computer, for instance, routes corporate callers to specialist account managers who know each company's terms, product specifications, purchase-order requirements, and so forth. Sometimes Dell's corporate reps know more about a customer's company and its PC requirements than the caller does himself!

- Interact more cost-efficiently and effectively with your customers. Separate 'live' sales calls from routine requests, driving the routine calls into more and more automated, self-service channels. Use your call centre to pre-qualify prospects and ensure that personal sales calls are more efficient. Promote your URL to callers who are placed on hold because all the service reps are busy. And make your interaction centre more effective by measuring the right variables. 


\section{Customise}

\section{Become your customers' 'trusted agent $^{\prime}$}

Rather than tallying how fast you get your customers off the phone, you really should want to talk more with the most interested and growable customers. In addition to hold times and call abandonment rates, measure the ratio of complaints handled on the first call, and the ratio of incoming leads converted to sales calls. Compensate your friendliest, most respectful service reps better - their smiles are understood and appreciated across phone lines.

- Customise the treatment your customers receive. The only costefficient way to customise the treatment of individual customers is to rely on mass customisation principles - digitally combining a product or a service from dozens, or hundreds, of pre-configured modules. Chordiant, a customer interaction centre software firm, allows its clients to change the process they use to handle calls in real time, using a simple, object-oriented dashboard - in effect 'mass customising' the call centre management process. When a promotion runs its course prematurely, or when a competitor fires an unexpected salvo, having the capability to implement and manage different strategies for different customers, quickly and costefficiently, will spell the difference between success and failure.

This is the methodology behind one-to-one marketing. But one-to-one marketing is also a common-sense process, founded on the longestablished principles of listening carefully to customers and trying to accommodate them as best you can. So rather then simply talking about how much you value customer interaction, why not make a genuine effort to discover what they're really saying and how your company really treats them? If you're a CEO or marketing vice-president, spend a day working a shift in your customer interaction centre. Tell your salesforce, starting with the sales managers, to do the same. Or have your interaction centre manager make a recording of 30 minutes of random inbound interactions, once a week. Then distribute the tape to your managers, so they can listen to it in their cars on the way to work. However you do it, at your customer interaction centre, more than at any other location in the company, you'll have a ringside seat to see first hand how your company treats its customers — solving their problems, selling them products, boosting your brand.

Creating a customer interaction centre that can remember a customer from one transaction to another and do so in a rational, integrated way can have more benefits than just smoother communications between a company and its customers. For those enterprises with the courage and vision to realise it, a customer interaction centre can become an indispensable tool in gaining a position of trust in the mind of the customer. In a world of increasingly commoditised products and services, a relationship founded on trust provides the basis for the only genuinely sustainable competitive advantage.

Think about it. If you didn't trust your bank, would you give it every single iota of financial information about you in order to qualify for a loan? If you didn't have faith that your insurance company wasn't sharing your vital information with other 
A new corporate culture

\section{At your request}

companies, would you even think about filling out all those forms? Only in a relationship of trust can information pass back and forth freely between buyer and seller.

For this reason companies must focus on becoming their customers' 'trusted agent', and this effort implies, at most firms, a noticeable change in the corporate culture.

A trusted agent takes customers' needs to heart, making them its paramount consideration, and always acting in their own interest. In a more traditional, transaction-based business model, buyer and seller are adversaries, no matter how much the seller may try not to act the part. There is no past or future to the relationship with a customer. There is only the immediate transaction.

But in a one-to-one marketing universe, the purchase transaction exists within the context of previous transactions and future ones that will follow. The buyer and seller collaborate, with the buyer specifying the product or service he or she wants, and the seller responding with some change in behaviour appropriate for that buyer. The seller and buyer remember each other from previous transactions and create a true interactive relationship for future transactions to flourish. In the context of this kind of relationship, the buyer and seller must each be able to trust the other, and the more they trust each other, the richer the relationship can be.

Becoming a trusted agent is no simple task. Translating the trusted agent philosophy into commercial reality involves more than simple policy decisions on the enterprise's part. Becoming a trusted agent for your customer requires a deep, cultural change in attitude at most firms.

One company trying to make this cultural shift is First USA, one of the USA's largest issuers of Visa, MasterCard, and private-label credit cards. It has launched 'At Your Request', an ambitious service programme for customers in good standing that, according to Richard Vague, chairman and CEO of First USA, gives clients a 'personal assistant, concierge, researcher and travel agent, all in one'. And, since At Your Request is based on customers interacting with the service via telephone, fax, e-mail, or the Web, First USA's call centre plays a crucial role in the programme's success or failure.

The programme includes a reminder service called Just-in-Time, which asks users to list anniversaries, special events, and other important dates; the customer is asked when and how she would like to be notified of these events. A Preference Profile asks for names and birthdays of everyone in the user's immediate family as well as their hobbies, favourite magazines, sports, and cultural pursuits. First USA uses this information not only to tailor specific reminders and offers to individual customers, but to show the customer that it anticipates their needs.

Vague says the benefit to First USA of the At Your Request programme can't be measured exclusively in terms of credit card activity or immediate revenue.

\section{'It occurred to us that playing the role of concierge would do two things. First of all, it would augment our knowledge}


Trusted agent dilemmas

\section{Best-interests marketing}

\section{of the customer. If somebody calls up and says, "What's the best deal on a kayak?", that tells us a lot about him. Second, our being genuinely helpful would create a feeling of trust in the customer's mind. So the customer wouldn't just see us as a big institution coming at them to sell something.'}

To create a position as a genuine trusted agent you must develop a genuine empathy for the customer. This can be expensive, of course, with databases, call centres, websites, mass-customised service applications, and so forth. But, as one UK consultant put it recently, if you think customer empathy is expensive, then you should try apathy.

In addition, empathising with your customers - becoming their trusted agent - can create unexpected dilemmas. For First USA, the dilemma boiled down to balancing its own commercial interests against the need to provide objective, impartial advice to its customers.

At Your Request customers are required to use their First USA credit cards if their enquiry results in a purchase, although fewer than half the calls to At Your Request do generate purchases. But even if every call generated an expensive purchase, the credit card transaction fee earned by First USA could not possibly pay for the cost of simply handling the call. So, commissions from service and merchandise vendors are also the primary means employed to offset the programme's cost. First USA has made arrangements with a number of vendors to receive commissions for customers sent to them, in much the same way as a hotel concierge might receive a commission from a restaurant for booking a good table for you.

But this is what creates the dilemma for First USA. Suppose, for instance, that a customer were to request information on the best CD player for her living room. Should First USA only show her CD players from companies with which it has made a sales arrangement? It's clearly in the bank's interest to promote those deals, but what's the right way to balance this commercial interest against the company's other objective - serving as a trusted agent for its customers' own best interests? What would you do, if you were in charge of First USA's programme?

While you're wrestling with how to resolve this dilemma (and there is a simple answer), let's see how another firm deals with its own trusted agent issue.

BT Cellnet, one of the UK's four cellular phone networks, operates in a very competitive and commoditised market. In cooperation with Devon Direct, an American marketing and advertising firm, BT Cellnet developed the 'First Programme', to help establish a trusted agent relationship with its customers. First Programme, as a concept, is simple: always charge your customers the lowest price. How it works: each quarter BT Cellnet's customers receive a First Check Up, a highly customised statement showing how much they would have paid for their calls if they had been using any of the other BT Cellnet standard calling plans. If a customer's bill would have been less using one of these other plans, then the company refunds the difference. It's that simple.

Finding the lowest price for its customer is BT Cellnet's way to practise what is often called 'best-interests marketing' — putting the 


\section{Competing in a commoditised market}

\section{Conclusion}

customer's own best interests ahead of the corporation's short-term economic interests. It is a surefire way to become a trusted agent. But imagine going to the CEO with this policy and trying to show an 'ROI' on it. How can a company possibly justify doing this? As a traditional marketer, you simply can't. Business success derives from maximising your product transactions and current sales revenue. Giving revenue back is simply not economic. But to a one-to-one marketer, measuring success in terms of the long-term value of customer relationships, it's not that difficult a programme to justify at all. And once you implement it, think about the message you are sending to everyone who works for you - everyone who answers the phone, produces a product, handles an enquiry, services a customer. It says the customer's own interests are paramount. It says you want to be your customer's trusted agent.

Results for BT Cellnet have been spectacular. Before the programme, BT Cellnet was in last place among the UK's four government-regulated cellular telephone networks. With the introduction of First Programme, however, the company has shot up to second place behind long-time leader Vodafone. More than half of BT Cellnet's eligible base of 1.8 million customers converted to First Programme in its first seven months, significantly reducing churn.

BT Cellnet knows that a relationship founded on trust will give it a long-term advantage over its competitors. By offering its customers the lowest possible prices for its service, BT Cellnet is collaborating with its customers and keeping their best interests in mind. The profits from these loyal customers should last for years.

So, did you guess how First USA resolved its own 'trusted agent' dilemma? Here's their policy. When a customer makes a request for a product recommendation, At Your Request lists for her a variety of products, referencing some impartial third party whenever possible perhaps Consumer Reports, or maybe some other magazine or directory. Then, in addition to providing this listing, the bank offers the customer a special deal if she chooses to buy a product from one of the companies with which First USA has a business relationship. In effect, First USA shares with its customer the benefit of the special price or rebate that it has negotiated with the supplier.

When you think about it, this is a simple policy. A trusted agent will disclose its relationships to a customer, and then use incentives to try to promote particular choices by the customer.

Customer interactivity is the key ingredient for generating ongoing, one-to-one relationships with individual customers. And while relationships are designed to provide customer convenience and deliver customer loyalty to the company as a result, they must be built, first, on trust. Often, this will have a wide-ranging impact on how a company sees its own mission. But effective customer interaction presupposes a trusting relationship.

Trust is the true currency of all commerce.

(C) Copyright Peppers and Rogers Group. All rights reserved 